\title{
COST REDUCTION BY COMBINED CAROTID ENDARTERECTOMY AND CORONARY ARTERY BYPASS GRAFTING
}

Pat O. Daily, $\mathrm{MD}^{\mathrm{a}}$

Richard K. Freeman, MD ${ }^{b}$

Walter P. Dembitsky, $\mathrm{MD}^{\mathrm{a}}$

Robert M. Adamson, MD ${ }^{\mathrm{a}}$

Ricardo J. Moreno-Cabral, MD

Stephen Marcus, PA-C

Jeffrey A. Lamphere, PA-C ${ }^{a}$

\begin{abstract}
A significant cost reduction is likely if patients who require coronary artery bypass grafting with significant carotid stenosis have simultaneous carotid endarterectomy and bypass grafting, provided risk is not increased. To investigate this issue, we retrospectively identified cases from February 1977 to May 1994 with first-time isolated carotid endarterectomy, coronary bypass, or combined procedures. In the isolated carotid endarterectomy population, median age was 69 years and $58 \%(85 / 146)$ were male, as compared with 68 years and $68 \%(68 / 100)$ male in the combined group; median age of the coronary bypass cohort was 65 years and $76 \%(381 / 500)$ male. A significantly higher percentage of patients in the coronary bypass versus combined group were in New York Heart Association functional class IV. In the combined group there was a significantly higher incidence of older age, diabetes, hypertension, hyperlipidemia, renal failure, and congestive heart failure. There was no difference among the three groups with respect to hospital mortality $(0 \%, 3.4 \%$, and $4.0 \%$, respectively) and permanent stroke $(0.7 \%, 1.2 \%$, and $0 \%$, respectively). Hospital costs were $\$ 4,896, \$ 10,959$ and $\$ 11,089$, respectively, with a savings of $\$ 4,766(30 \%)$, and Medicare hospital reimbursement was $\$ 8,575, \$ 23,071$, and $\$ 23,071$, respectively, with a savings of $\$ 10,077(25.3 \%)$. Thus, in appropriate patients, a combined procedure is cost effective, eliminating a second surgical procedure and the cost of the postoperative stay ( $3.7 \pm 2.4$ days) associated with isolated carotid endarterectomy. Risk of permanent stroke or death is not increased. (J Thorac Cardiovase Surg 1996;111:1185-93)
\end{abstract}

$\mathrm{N}$ umerous previous reports have been directed at resolving the issue of whether patients undergoing coronary artery bypass grafting $(\mathrm{CABG})$ with significant carotid disease ( $\geq 60 \%$ stenosis) should have simultaneous or staged procedures or no carotid endarterectomy (CEA) at all. This question is additionally complicated by the presence or absence of cerebral symptoms. In some of these reports the risk of combined procedures is significantly higher than the additive risk of staged procedures, whereas in other reports there is no increased risk. No

From Sharp Memorial Hospital ${ }^{\mathrm{a}}$ and the Naval Regional Medical Center, San Diego, Calif.

Read at the Twenty-first Annual Meeting of The Western Thoracic Surgical Association, Coeur d'Alene, Idaho, June 21-24, 1995.

Received for publication June 21, 1995; revisions requested Nov. 25, 1995; revisions received Feb. 14, 1996; accepted for publication March 1, 1996.

Address for reprints: Pat O. Daily, MD, 8010 Frost St., Suite 501, San Diego, CA 92123.

$12 / 6 / 73243$ unequivocal evidence has surfaced to suggest that patients undergoing $\mathrm{CABG}$ with significant carotid disease are exposed to increased risk of stroke or death (or both) in the perioperative phase. However, many authors have indicated that CEA reduces the incidence of late stroke in patients with $60 \%$ stenosis or more who have symptoms and, recently, in patients who are symptom-free. This latter group has substantially increased the number of patients who are potential candidates for combined procedures.

Actual cost savings, if the risks of permanent stroke and death are not increased, have not been previously reported for combining CEA and CABG. Therefore, we evaluated consecutive series of patients having isolated single CEA, isolated CABG, and combined procedures with respect to risk and cost savings.

\section{Patients and methods}

Selection criteria. From February 1977 to May 1994, all consecutive patients undergoing isolated CEA were se- 
Table I. Patient descriptors-history and physical characteristics

\begin{tabular}{|c|c|c|c|c|}
\hline Variable & Isolated $C A B G$ & Isolated $C E A$ & $\begin{array}{c}\text { Combined } \\
C A B G+C E A\end{array}$ & $\begin{array}{c}p \text { Value* } \\
\text { (overall) }\end{array}$ \\
\hline No. & 503 & 146 & 100 & \\
\hline Age $(y r)$ & $63.6 \pm 10.3(<0.001)$ & $69.4 \pm 8.9(0.220)$ & $68.1 \pm 7.5$ & $<0.001$ \\
\hline Male & $75.8(0.134)$ & $58.2(0.156)$ & 68.0 & $<0.001$ \\
\hline \multicolumn{5}{|l|}{ Previous myocardial infarction } \\
\hline$<6 \mathrm{mo}$ & $30.6(0.043)$ & $4.1(<0.001)$ & 20.0 & $<0.001$ \\
\hline$>6 \mathrm{mo}$ & 22.9 & 24.7 & 22.0 & 0.868 \\
\hline Unstable angina & $75.0(0.777)$ & $3.4(<0.001)$ & 73.0 & $<0.001$ \\
\hline NYHA class IV & $51.1(0.236)$ & $2.1(<0.001)$ & 44.0 & $<0.001$ \\
\hline Diabetes & $17.1(0.026)$ & $16.4(0.059)$ & 27.3 & 0.046 \\
\hline Hypertension & $45.1(<0.001)$ & $71.9(0.603)$ & 76.8 & $<0.001$ \\
\hline Hyperlipidemia & $16.5(0.017)$ & $25.3(0.850)$ & 27.3 & 0.007 \\
\hline Congestive heart failure & 9.2 & 11.0 & 16.0 & 0.119 \\
\hline Renal failure & $4.8(<0.001)$ & $6.9(0.035)$ & 16.2 & $<0.001$ \\
\hline Pulmonary disease & 14.1 & 15.1 & 23.5 & 0.064 \\
\hline Current smoking & 18.3 & 26.7 & 21.0 & 0.082 \\
\hline Peripheral vascular disease $\dagger$ & $9.2(<0.001)$ & $21.9(0.015)$ & 37.0 & $<0.001$ \\
\hline Previous vascular surgerył & $4.0(0.137)$ & $17.1(0.061)$ & 8.0 & $<0.001$ \\
\hline Central nervous system symptoms & NA & 76.7 & 21.4 & $<0.001$ \\
\hline Bruit & $4.4(<0.001)$ & $58.9(0.633)$ & 55.0 & $<0.001$ \\
\hline \multicolumn{5}{|l|}{ Blood pressure $(\mathrm{mm} \mathrm{Hg})$} \\
\hline Systolic & $141 \pm 18(<0.001)$ & $144 \pm 22(0.072)$ & $139 \pm 20$ & $<0.001$ \\
\hline Diastolic & $77 \pm 13(0.072)$ & $79 \pm 13(0.133)$ & $77 \pm 13$ & $<0.001$ \\
\hline
\end{tabular}

Entries are mean \pm standard deviation for continuous variables and percentages for categoric data. Values in parentheses are $p$ values for comparison with combined CABG + CEA group by $t$ tests or continuity-corrected $\chi^{2}$ analysis.

* From analysis of variance or $\chi^{2}$.

$\dagger$ Abdominal aorta, thoracic aorta, iliac, femoral, popliteal, subclavian, or vertebral artery.

$\$$ Abdominal aortic aneurysm, aortoiliac, aortofemoral, or femoral-distal.

lected for comparison. The patients in this cohort had unilateral carotid disease that was hemodynamically significant, defined as $60 \%$ stenosis or more, and demonstrated by carotid arteriography. Exclusion criteria were previous stroke, CEA, CABG, or multiple peripheral vascular procedures. Throughout the same period 503 patients undergoing isolated CABG with no significant carotid stenoses, no other cardiac disease, and no prior sternotomy were randomly selected from a group of more than 3000 patients. From a statistical standpoint this was an adequate number of patients for comparison purposes. Exclusion criteria were previous peripheral vascular and cardiac procedures, as well as other cardiac disease. Our standard policy, except in emergencies, is to perform carotid duplex scanning in all patients having procedures that involve cardiopulmonary bypass (CPB). The same selection and exclusion criteria were applied to patients having combined CEA and CABG.

Patients in all three groups were evaluated for certain historical aspects, selected physical findings, coronary and carotid arteriographic findings, as well as selected intraoperative considerations such as the procedures performed and intraoperative findings. Outcomes such as selected complications including permanent neurologic deficit and hospital mortality were evaluated. These characteristics are defined in Tables I through IV.

Cost evaluation. Hospital costs were derived from a computer database comprised of cost related to the operating room personnel and equipment, intensive care unit, pharmacy, laboratory services, respiratory therapy, central services, radiology, cardiac rehabilitation, vascular laboratory, cardiology/EKG, and nutritional supplements. The costs for five patients from each group (CEA, CABG, and combined) with average hospital stays were selected at random and averaged. Exclusion criteria were previous cardiac operations or stroke and any cardiac operation in addition to CABG for the study group.

Current cost data regarding hospital costs and Medicare DRG 107 (without cardiac catheterization) reimbursement are presented in Table V.

Surgical methods. All patients undergoing CEA were intraoperatively monitored with electroencephalography. A shunt was not used unless electroencephalographic changes indicated cerebral ischemia of the operative side. In these instances a shunt was used for the performance of endarterectomy and partial closure of the arteriotomy. In the majority of cases, primary closure of the carotid arteriotomy was performed. However, a patch graft of autogenous saphenous vein or polytetrafluoroethylene* was used when deemed necessary because of the relatively small size of the artery.

Standard CPB with cannulation of the ascending aorta and bicaval cannulation via the right atrium was used for patients undergoing CABG. In virtually all of the patients,

\footnotetext{
*Polytetrafluoroethylene manufactured by W. L. Gore \& Asso-
} ciates, Inc., Elkton, Md., and Impra, Inc., Flagstaff, Ariz. 
Table II. Patient descriptors-angiographic and surgical data

\begin{tabular}{|c|c|c|c|}
\hline Variable & $\begin{array}{c}\text { Isolated } \\
C A B G\end{array}$ & $\begin{array}{c}\text { Combined } \\
C A B G+C E A \\
\end{array}$ & $\begin{array}{c}p \\
\text { Value }\end{array}$ \\
\hline No. & 503 & 100 & \\
\hline \multicolumn{4}{|l|}{ Extent of disease } \\
\hline Single & 4.6 & 1.0 & \\
\hline Double & 23.3 & 23.2 & 0.249 \\
\hline Triple & 72.2 & 75.8 & \\
\hline Left main & 11.7 & 20.0 & 0.038 \\
\hline \multicolumn{4}{|l|}{ Scheduling } \\
\hline Elective & 80.5 & 93.0 & \\
\hline Urgent & 7.4 & 5.0 & 0.005 \\
\hline Emergency & 12.1 & 2.0 & \\
\hline \multicolumn{4}{|l|}{ Time (min) } \\
\hline $\mathrm{CPB}$ & $77 \pm 29$ & $73 \pm 24$ & 0.136 \\
\hline Aortic crossclamp & $35 \pm 15$ & $34 \pm 14$ & 0.639 \\
\hline \multicolumn{4}{|l|}{$\begin{array}{l}\text { No. of times aorta cross- } \\
\text { clamped }\end{array}$} \\
\hline $0-2$ & 10.1 & 5.6 & \\
\hline $3-4$ & 61.1 & 73.0 & 0.092 \\
\hline $5+$ & 28.9 & 21.4 & \\
\hline \multicolumn{4}{|l|}{ No. of grafts } \\
\hline $1-2$ & 11.1 & 6.0 & \\
\hline 3 & 20.5 & 27.0 & \\
\hline 4 & 26.6 & 38.0 & 0.020 \\
\hline 5 & 20.5 & 17.0 & \\
\hline $6+$ & 21.3 & 12.0 & \\
\hline Average no. of grafts & $4.2 \pm 1.3$ & $4.0 \pm 1.0$ & NS \\
\hline \multicolumn{4}{|l|}{ Myocardial protection } \\
\hline Cardioplegia & 5.6 & 8.0 & \\
\hline Intermittent crossclamping & 94.4 & 92.0 & 0.480 \\
\hline $\begin{array}{l}\text { Lowest perfusion tempera- } \\
\text { ture }\left({ }^{\circ} \mathrm{C}\right)\end{array}$ & $30.2 \pm 1.3$ & $30.1 \pm 1.5$ & NS \\
\hline Normal aorta & 96.6 & 92.9 & 0.151 \\
\hline
\end{tabular}

Entries are mean \pm standard deviation for continuous variables and percentages for categoric data. $p$ Value is from $t$ test or continuitycorrected $\chi^{2}$ test. $N S$, Not significant.

body temperature was maintained at $30^{\circ} \mathrm{C}$. Intermittent aortic crossclamping was used for performance of the distal grafts in more than $90 \%$ of patients with isolated CABG or combined procedures, as previously described. ${ }^{1}$ In the remaining patients multiple-dose cardioplegia with single aortic crossclamping was used at the discretion of the primary surgeon to reduce the risk of atheroembolization or if the ascending aorta was arteriosclerotic as assessed by palpation. Since July 1992, all patients to undergo $\mathrm{CPB}$ procedures have been given vitamin $\mathrm{E}$, vitamin $\mathrm{C}$, and allopurinol by the following dose schedule: $600 \mathrm{mg}$ of allopurinol, 400 units of vitamin $\mathrm{E}$, and $500 \mathrm{mg}$ of vitamin C 8 hours and 4 hours before the operation. In all patients having both procedures, median sternotomy was first performed along with harvesting of the required saphenous veins or internal thoracic arteries. CEA was performed as described earlier. After completion of CEA, the incision in the neck was left open and a sump tube was placed in the incision for continued drainage during the performance of CABG.
Table III. Patient descriptors-angiographic and surgical data

\begin{tabular}{lccc}
\multicolumn{1}{c}{ Variable } & $\begin{array}{c}\text { Isolated } \\
\text { CEA }\end{array}$ & $\begin{array}{c}\text { Conibined } \\
\text { CABG }+ \text { CEA }\end{array}$ & $p$ Value \\
\hline No. & 146 & 100 & \\
Left CEA & 52.0 & 51.0 & 0.978 \\
Right CEA & 48.0 & 49.0 & \\
Stenosis* & & & \\
$<25 \%$ & 2.1 & 4.1 & \\
$25 \%-50 \%$ & 7.5 & 4.1 & \\
$51 \%-75 \%$ & 14.4 & 10.3 & 0.358 \\
$76 \%-99 \%$ & 76.0 & 80.4 & \\
$100 \%$ & 0.0 & 1.0 & \\
Ulceration* & & & \\
$\quad \geq 2$ mm & 30.8 & 18.0 & 0.034 \\
Scheduling & & & \\
$\quad$ Elective & 84.3 & 93.0 & \\
Urgent & 11.6 & 5.0 & 0.119 \\
$\quad$ Emergency & 4.1 & 2.0 & \\
Shunt used & 27.4 & 23.0 & 0.530 \\
Patch used & 14.4 & 10.0 & 0.411 \\
\hline Entries are percentages. & & \\
$p$ Value is from continuity-corrected $\chi^{2}$ test. & \\
*Ulceration in artery undergoing endarterectomy. & \\
& & & \\
& & &
\end{tabular}

Statistical methods. To compare demographic, histori$\mathrm{cal}$, and physical examination findings among the three groups of patients, we used an analysis of variance or $\chi^{2}$ test. When the overall $p$ value was significant, pair-wise tests were performed to compare each isolated group with the combined group ( $t$ tests and continuity-adjusted $\chi^{2}$ with the Bonferroni correction for two tests). Variables relevant to one isolated group were compared with those for the combined group by means of $t$ tests and continuity-adjusted $\chi^{2}$ tests. In instances in which all cell sizes were too small for a valid $\chi^{2}$ analysis, Fisher's exact test was used.

\section{Results}

The isolated and combined groups differed with respect to a number of demographic, historical, and physical examination findings (see Table I). The combined group was significantly older and more likely to be male than the isolated CABG group but was not significantly different from the isolated CEA group. The prevalence of recent myocardial infarction, history of unstable angina, and New York Heart Association anginal class IV was about the same for the combined and isolated CABG groups, but much lower for the isolated CEA group. The combined group did not differ from the isolated CEA group in history of diabetes, hypertension, hyperlipidemia, and renal failure but showed higher rates of these problems than seen in the isolated CABG group. The combined group had a higher rate of peripheral vascular disease than both groups 
Table IV. Results

\begin{tabular}{|c|c|c|c|}
\hline Variable & Isolated $C A B G$ & Isolated $C E A$ & Combined $C A B G+C E A$ \\
\hline No. & 503 & 146 & 100 \\
\hline \multicolumn{4}{|l|}{ Complications } \\
\hline Perioperative myocardial infarction & $1.6(1.000)$ & & 1.0 \\
\hline Bleeding necessitating reoperation & $5.8(1.000)$ & & 5.0 \\
\hline Leg wound infection & $4.4(1.000)$ & & 4.0 \\
\hline Respiratory insufficiency & $6.2(0.278)$ & & 9.0 \\
\hline Renal failure & $2.2(0.047)$ & & 6.0 \\
\hline Low cardiac output syndrome* & $6.4(0.490)$ & & 4.0 \\
\hline Neck hematoma & & $3.4(0.406)$ & 1.0 \\
\hline Neck infection & & $1.4(0.516)$ & 0 \\
\hline \multicolumn{4}{|l|}{ Morbidity and mortality } \\
\hline Permanent neurologic deficit & 1.2 & 0.7 & 0 \\
\hline Hospital mortality & 3.4 & 0 & 4.0 \\
\hline Total permanent neurologic deficit and hospital mortality & 4.6 & 0.7 & 4.0 \\
\hline Length of hospital stay (postoperative days) & $9.0 \pm 6.8$ & $3.7 \pm 2.4$ & $10.3 \pm 5.1$ \\
\hline
\end{tabular}

Entries are percentages or mean \pm standard deviation. $p$ Values (in parentheses) are from $t$ tests or Fisher's exact test comparing isolated and combined groups.

*Intraaortic balloon pump or inotropic support.

with isolated procedures. Despite an overall group difference for previous vascular operations, however, the rates seen in the isolated groups were not different from those for the combined groups after the Bonferroni correction to the significance level. The prevalence of carotid bruit in the combined group was similar to that observed for the isolated CEA group and much higher than that in the isolated CABG group. Neurologic symptoms were more common in the CEA group. Because of the large sample size for isolated CABG, the slightly elevated systolic blood pressure in the isolated CABG group was significantly higher than that in the combined group, whereas the even higher mean pressure in patients having isolated CEA was not different from that for the patients having combined procedures.

The extent of coronary artery disease and surgical data for the combined group and the isolated CABG group was fairly similar (see Table II). The combined group had a few more patients with triple vessel disease, but the overall distribution was not statistically different from that in the isolated group. However, left main disease was more prevalent in the combined group. The reason for the statistical difference between the groups with respect to the number of grafts implanted was that the combined group had a higher proportion of patients receiving four grafts, and the distribution was more even in the isolated group. However, the average number of grafts per patient was not significantly different. A higher percentage of patients with combined proce- dures had elective operations rather than urgent or emergency operations.

Patients in the combined group were also similar to those in the isolated CEA group with respect to carotid stenosis in the artery receiving the endarterectomy (see Table III). However, the isolated group contained a greater percentage of patients having ulceration of $2 \mathrm{~mm}$ or more. The smaller sample size for the isolated group resulted in a nonsignificant difference in the rates of elective, urgent, or emergency operations.

The rates of complications were low in all groups (see Table IV). The combined group did have a higher rate of renal failure than the isolated $\mathrm{CABG}$ group, but the rates of most other complications were lower than for the isolated groups although not significantly lower. Hospital mortality in patients with a combined procedure did not appear to be higher than those of the group with isolated CABG, and the length of stay in the hospital was not significantly increased. Hospital costs and Medicare reimbursement for DRG 107 (without cardiac catheterization) are listed in Table $\mathrm{V}$.

\section{Discussion}

Outcomes as compared with the literature. Since Bernhard, Johnson, and Peterson ${ }^{2}$ first reported combining CEA with $\mathrm{CABG}$, more than 40 publications ${ }^{3}$ have presented results and recommendations regarding the feasibility or the inappropriateness of performing the combined procedures. In 1991, Gugulakis, Kalodiki, and Nicolaides ${ }^{4}$ summarized 
Table V. Financial data-DRG 107 (without cardiac catheterization)

\begin{tabular}{lcccc}
\hline & \multicolumn{3}{c}{ Procedure } & \\
\cline { 2 - 4 } & CEA & CABG & Combined & Savings \\
\hline Hospital cost & $\$ 4,896$ & $\$ 10,959$ & $\$ 11,089$ & $\$ 4,766(30 \%)$ \\
Medicare DRG 107 hospital reimbursement & $\$ 8,575$ & $\$ 23,071$ & $\$ 23,071$ & $\$ 8,575(27.1 \%)$ \\
Professional fee reimbursement-DRG 107 & $\$ 2,681$ & $\$ 4,709$ & $\$ 6,050$ & $\$ 1,340(18.2 \%)$ \\
$\quad$ Surgical & $\$ 324$ & $\$ 601$ & $\$ 763$ & $\$ 162(17.6 \%)$ \\
$\quad$ Anesthesia & $\$ 11,580$ & $\$ 28,381$ & $\$ 29,884$ & $\$ 10,077(25.3 \%)$ \\
$\quad \begin{array}{l}\text { Total Medicare savings-DRG } 107 \\
\quad \text { Total }\end{array}$ & & & & \\
\hline
\end{tabular}

the majority of these studies, ${ }^{2,24}$. The studies included 1444 patients with a combined permanent neurologic deficit rate of $2.4 \%$ and a hospital mortality rate of $4.2 \%$ for a combined morbidity and mortality rate of $6.6 \% .^{2,5-24}$ There is approximately an equal division between those recommending the combined procedure and those suggesting that CEA should not be performed simultaneously with $\mathrm{CABG} .{ }^{4}$ In reports published since the 1991 paper of Gugulakis, Kalodiki, and Nicolaides, ${ }^{4}$ and earlier results not described by them, an additional 691 patients have undergone combined procedures with a permanent neurologic deficit rate of $4.5 \%$ and a mortality rate of $4.9 \%$, resulting in an overall total morbidity and mortality of 9.4\% ${ }^{25-30}$ (Table VI). Clearly, the overall results of combined CEA and CABG have not improved with time. In 1992 Bass and associates ${ }^{26}$ reported a permanent neurologic deficit rate of $12 \%$ and a hospital mortality rate of $12 \%$ in a series of 99 patients from three centers. Not surprisingly, they suggested staged rather than combined procedures.

The reported incidence of permanent neurologic deficit related to $\mathrm{CPB}$ without CEA ranges from $0.8 \%{ }^{1}$ to $6.0 \%{ }^{7}$ with an average of approximately $2.0 \% .^{4}$ Mortality associated with isolated CABG currently averages $3.3 \% .^{31}$ Consequently, the average permanent neurologic deficit and mortality rate for $\mathrm{CABG}$ is $5.3 \%$. Added to the average $2 \%$ morbidity and mortality rate for $\mathrm{CEA},{ }^{4}$ there is a $7.3 \%$ average permanent neurologic deficit and hospital mortality rate for CEA and CABG performed separately. This is higher than in the report of Gugulakis, Kalodiki, and Nicolaides, ${ }^{4}$ with a total permanent neurologic deficit and hospital mortality rate of $6.6 \%$. However, some authors ${ }^{17,32-34}$ have suggested that combined procedures should be performed only for neurologic symptoms, whereas others, ${ }^{13}, 18,19,30,35-37$ with results equal to or better than combined permanent neurologic deficit and
Table VI. Results in combined $C E A$ and $C A B G$ group since 1991 report of Gugulakis, Kalodiki, and Nicolaides ${ }^{4}$

\begin{tabular}{lrccr} 
& No. & \multicolumn{1}{c}{ PND } & HM & Total \\
\hline Akins et al. $^{25}$ & 200 & $2.5 \%(5)$ & $3.5 \%(7)$ & $6.0 \%$ \\
Bass et al. $^{26}$ & 99 & $12.0 \%(12)$ & $12.0 \%(12)$ & $24.0 \%$ \\
Halpin et al. $^{27}$ & 133 & $2.3 \%(3)$ & $1.5 \%(2)$ & $3.8 \%$ \\
Vassilidze et al. $^{28}$ & 33 & $6.0 \%(2)$ & $6.0 \%(2)$ & $12.0 \%$ \\
Rizzo et al. $^{29}$ & 127 & $5.5 \%(7)$ & $5.5 \%(7)$ & $11.0 \%$ \\
Maki et al. $^{30}$ & 99 & $2.0 \%(2)$ & $4.0 \%(4)$ & $6.0 \%$ \\
& 691 & $4.5 \%(31)$ & $4.9 \%(34)$ & $9.4 \%$ \\
\hline
\end{tabular}

$P N D$, Permanent neurologic deficit; $H M$, hospital mortality; Total, operative mortality and permanent neurologic deficit.

hospital mortality rates of $7.0 \%$, have included neurologically asymptomatic patients. One reason for performing combined CEA and $\mathrm{CABG}$ was increased risk of cerebral vascular accident for patients undergoing $\mathrm{CABG}$ with significant carotid disease, as suggested initially by Fields ${ }^{38}$ and later by Faggioli, Curl, and Ricotta. ${ }^{39}$ However, other authors have not identified an increased risk of stroke in patients with significant carotid stenosis having isolated CABG. ${ }^{40,41}$ Barnes and coworkers ${ }^{42,43}$ concluded that although asymptomatic carotid disease correlates poorly with perioperative stroke, the risk of late stroke and cardiac death is high.

Despite the fact that patients undergoing a combined procedure had more widespread arteriosclerosis and a greater incidence of diabetes, renal failure, and left main coronary disease than those receiving only CABG, the results of this study do not provide any evidence of a consistent trend for higher complication or mortality rates than for those undergoing isolated procedures. The efficacy of CEA for symptomatic carotid disease was substantiated by the North American Symptomatic Carotid Endarterectomy Trial. ${ }^{44}$ Earlier reports ${ }^{45-50}$ suggested, 
but did not prove, that CEA for asymptomatic stenosis in the range of $70 \%$ to $80 \%$ resulted in improved long-term results. However, these data continued to be debated until the recent publication of the Executive Committee for the Asymptomatic Carotid Artery Study, ${ }^{51}$ proving unequivocally that patients with asymptomatic $60 \%$ stenosis or more of the carotid artery had a $53 \%$ reduction in ipsilateral stroke over 5 years provided that CEA could be performed with a combined permanent neurologic deficit and hospital mortality rate of $3 \%$ or less. Consequently, this study regarding patients who are free of symptoms has significantly increased the potential number of patients who could benefit from combined CEA.

Selection of patients. Some patients undergoing combined CEA and CABG have had a variety of carotid lesions. These include both symptomatic and asymptomatic lesions ${ }^{52,53}$ and, in one study, bilateral carotid occlusion. ${ }^{54}$ These lesions may result in a higher incidence of both permanent neurologic deficit and mortality. Similarly, in other studies patients undergoing CABG have had cardiac procedures such as valve replacement. ${ }^{55}$ Furthermore, patients with $\mathrm{CABG}$ reoperations or valve replacement (or both) are at increased risk and have been included. ${ }^{31,56}$ The net effect of these variables is to confound interpretation of the results. Therefore, to simplify comparison of groups, we randomly selected 503 patients between February 1977 and May 1994 undergoing first-time sternotomy with isolated CABG. Similarly, patients undergoing isolated CEA had only single carotid disease. Patients selected for the combined group underwent CABG with no additional cardiac procedures and stenosis of only one carotid artery without stenosis or occlusion of the other carotid artery. Therefore, it was thought that comparison of these groups would result in more accurate prediction of outcomes for combined CABG and CEA.

Cost evaluation. Hospital costs were determined from a computer database described in the Patients and methods section. Combining CEA and CABG resulted in a savings to the hospital of $\$ 4766$ or $30 \%$ (see Table V). However, determination of the reimbursement of hospital and professional fee components was complicated by numerous health insurance plans associated with frequent changes in reimbursement schedules. These changes were so frequent and of such magnitude that comparison was, essentially, impossible. Therefore, we selected recent patients undergoing the combined proce- dure, isolated CEA, and isolated CABG for comparison who primarily had Medicare reimbursement. These comparisons, as seen in Table V, indicate that the reduction in reimbursement is $\$ 8575(27.1 \%)$ for the hospital component, $\$ 1,340$ $(18.21 \%)$ for the surgical fee, and $\$ 162(17.6 \%)$ for the anesthetic fee for a total savings of $\$ 10,077$ $(25.3 \%)$ for DRG 107.

Inferences. Our data indicate that combined CEA and CABG can be performed in this group of selected patients with an incidence of permanent neurologic deficit and hospital mortality no greater than for isolated CABG alone. However, much larger sample sizes would be required to conclusively rule out this possibility. The incidence of permanent neurologic deficit and hospital mortality may be higher in patients with other risk factors such as reoperation, additional procedures, and contralateral carotid disease. Because it has recently been demonstrated that patients with asymptomatic carotid disease with $60 \%$ stenosis or more are conferred significant long-term reduction of risk of stroke and death, it is rational to perform CEA with CABG from the standpoint of both convenience to the patient and cost savings to the hospital and reimbursing agency. The magnitude of these savings is $\$ 4766$ (30\%) for hospital costs and $\$ 8575(27.1 \%)$ for Medicare reimbursement of hospital costs. There is an additional savings to Medicare of $\$ 1340$ $(18.2 \%)$ for the surgical fee component and $\$ 162$ $(17.6 \%)$ for the anesthetic fee component.

We thank Elizabeth A. Gilpin, MS, for her assistance with the statistical data for this manuscript.

\section{REFERENCES}

1. Daily PO. Early and five-year results for coronary artery bypass grafting: a benchmark for percutaneous transluminal coronary angioplasty. J Thorac Cardiovasc Surg 1989;97:6777.

2. Bernhard VM, Johnson WD, Peterson JJ. Carotid artery stenosis: association with surgery for coronary artery disease. Arch Surg 1972;105:837-40.

3. Newman DC, Hicks RG. Combined carotid and coronary artery surgery: a review of the literature. Ann Thorac Surg 1988;45:574-81.

4. Gugulakis A, Kalodiki E, Nicolaides AN. Combined carotid endarterectomy and coronary artery bypass grafting: a literature review. Int Angiol 1991;10:167-72.

5. Faidutti B, Steichen FM, Thevoz F, Hahn CJ. Coronary artery and associated aortic or major arterial atherosclerosis: one-stage surgical management. Arch Surg 1972;105:711-4.

6. Urschel HC Jr, Ruzzuk MA, Gardner MA. Management of concomitant occlusive disease of the carotid and coronary arteries. J Thorac Cardiovasc Surg 1976;72:829-34. 
7. Mehigan JT, Buch WS, Pipkin RD, Fogarty TJ. A planned approach to coexistent cerebrovascular disease in coronary artery bypass candidates. Arch Surg 1977;112:1403-9.

8. Okies JE, McManus Q, Starr A. Myocardial revascularization and carotid endarterectomy: a combined approach. Ann Thorac Surg 1977;23:560-3.

9. Hertzer NR, Loop FD, Taylor PC, Beven EG. Staged and combined surgical approach to simultaneous carotid and coronary vascular disease. Surgery 1978;84:803-11.

10. Rice PL, Pifarré R, Sullivan HJ, Montoya A, Bakhos M. Experience with simultaneous myocardial revascularization and carotid endarterectomy. J Thorac Cardiovasc Surg 1980; 79:922-5.

11. Craver JM, Murphy DA, Jones EL, et al. Concomitant carotid and coronary artery reconstruction. Ann Surg 1982; 6:712-20.

12. Schwartz RL, Garrett JR, Karp RB, Kouchoukos NT. Simultaneous myocardial revascularization and carotid endarterectomy. Circulation 1982;66(Suppl):I97-101.

13. Emery RW, Cohn LH, Whittemore AD, Mannick JA, Couch NP, Collins JJ Jr. Coexistent carotid and coronary artery disease. Arch Surg 1983;118:1035-8.

14. Hertzer NR, Loop FD, Taylor PC, Beven EG. Combined myocardial revascularization and carotid endarterectomy: operative and late results in 331 patients. $\mathbf{J}$ Thorac Cardiovasc Surg 1983;85:577-89.

15. O'Donnell TF Jr, Callow AD, Willet C, Payne D, Cleveland RJ. The impact of coronary artery disease on carotid endarterectomy. Ann Surg 1983;198:705-12.

16. Ivey TD, Strandness DE, Williams DB, Langlois Y, Misbach GA, Kruse AP. Management of patients with carotid bruit undergoing cardiopulmonary bypass. J Thorac Cardiovasc Surg 1984;87:183-9.

17. Jones EL, Craver JM, Michalik RA, et al. Combined carotid and coronary operations: when are they necessary? J Thorac Cardiovasc Surg 1984;87:7-16.

18. Perler BA, Burdick JF, Williams GM. The safety of carotid endarterectomy at the time of coronary artery bypass surgery: analysis of results in a high-risk patient population. J Vasc Surg 1985;2:558-63.

19. Cosgrove DM, Hertzer NR, Loop FD. Surgical management of synchronous carotid and coronary artery disease. J Vasc Surg 1986;3:690-4.

20. Marinelli G, Turinetto B, Bombardini T, Dozza F, Pierangeli V, Pierangeli A. Surgical approach to combined carotids and coronary lesions. Int Angiol 1987;6:393-6.

21. Lubicz S, Kelly A, Field PL, et al. Combined carotid and coronary surgery. Aust N Z J Surg 1987;57:593-7.

22. Vermeulen FEE, de Geest $R$, van den Pavoordt H, Eikelboom B. Simultaneous extensive extracranial and coronary revascularization: long-term follow-up to 13 years. Eur $\mathbf{J}$ Cardiothorac Surg 1988;2:113-23.

23. Minami K, Sagoo KS, Breymann T, Fassbender D, Schwerdt M, Körfer R. Operative strategy in combined coronary and carotid artery disease. J Thorac Cardiovasc Surg 1988;95: 303-9.

24. Minami K, Gawaz M, Ohlmeièr H, Vyska K, Körfer R. Management of concomitant occlusive disease of coronary and carotid arteries using cardiopulmonary bypass for both procedures. J Cardiovasc Surg 1989;30:723-8.

25. Akins CW, Moncure AC, Daggett WM, et al. Safety and efficacy of concomitant carotid and coronary artery operations. Ann Thorac Surg 1995;60:311-8.

26. Bass A, Krupski WC, Dilley RB, Bernstein EF. Combined carotid endarterectomy and coronary artery revascularization: a sobering review. Isr J Med Sci 1992;28:27-32.

27. Halpin DP, Riggins S, Carmichael JD, et al. Management of coexistent carotid and coronary artery disease. South Med J 1994;87:187-9.

28. Vassilidze TV, Cernaianu AC, Gaprindashvili T, Gallucci JG, Cilley JH Jr, DelRossi AJ. Simultaneous coronary artery bypass and carotid endarterectomy: determinants of outcome. Texas Heart Inst J 1994;21:119-24.

29. Rizzo RJ, Whittemore AD, Couper GS, et al. Combined carotid and coronary revascularization: the preferred approach to the severe vasculopath. Ann Thorac Surg 1992;54: 1099-109.

30. Maki HS, Kuehner ME, Ray JF III. Combined carotid endarterectomy and myocardial revascularization. Am J Surg 1989;158:443-5.

31. Clark RE. The STS Cardiac Surgery National Database: an update. Ann Thorac Surg 1995;59:1376-81.

32. Brener BJ, Brief DK, Alpert J, Goldenkranz RJ, Parsonnet $V$. The risk of stroke in patients with asymptomatic carotid stenosis undergoing cardiac surgery: a follow-up study. J Vasc Surg 1987;5:269-79.

33. Graor RA, Hertzer NR. Management of coexistent carotid artery and coronary artery disease. Stroke 1988;19:1441-4.

34. Ivey TD. Combined carotid and coronary disease--a conservative strategy. J Vasc Surg 1986;3:687-9.

35. Cambria RP, Ivarsson BL, Akins CW, Moncure AC, Brewster DC, Abbott WM. Simultaneous carotid and coronary disease: safety of the combined approach. J Vasc Surg 1989;9;56-64.

36. Matar AF. Concomitant coronary and cerebral revascularizaton under cardiopulmonary bypass. Ann Thorac Surg 1986; 41:431-5.

37. Newman DC, Hicks RG, Horton DA. Coexistent carotid and coronary arterial disease: outcome in 50 cases and method of management. J Cardiovasc Surg 1987;28:599-606.

38. Fields WS. Neurologic disorders related to alterations in blood pressure. Cardiovasc Res Cent Bull 1964;2:65-72.

39. Faggioli GL, Curl GR, Ricotta JJ. The role of carotid screening before coronary artery bypass. J Vasc Surg 1990; 12:724-31.

40. Schultz RD, Sterpetti AV, Feldhaus RJ. Early and late results in patients with carotid disease undergoing myocardial revascularization. Ann Thorac Surg 1988;45:603-9.

41. Breslau PJ, Fell G, Ivey TD, Bailey WW, Miller DW, Strandness DE. Carotid arterial disease in patients undergoing coronary artery bypass operations. J Thorac Cardiovasc Surg 1981;82:765-7.

42. Barnes RW, Liebman PR, Marszalek PB, Kirk CL, Goldman MH. The natural history of asymptomatic carotid disease in patients undergoing cardiovascular surgery. Surgery 1981;90: 1075-83.

43. Barnes RW, Nix ML, Sansonetti D, Turley DG, Goldman MR. Late outcome of untreated asymptomatic carotid disease following cardiovascular operations. J Vasc Surg 1985; 2:843-9.

44. North American Symptomatic Carotid Endarterectomy Trial Collaborators. Beneficial effect of endarterectomy in symp- 
tomatic patients with high-grade carotid stenosis. N Engl J Med 1991;325:445-53.

45. Moneta GL, Taylor DC, Nicholls SC, et al. Operative versus nonoperative management of asymptomatic high-grade internal carotid artery stenosis: improved results with endarterectomy. Stroke 1987;18:1005-10.

46. Rosenthal D, Rudderman R, Borrero E, et al. Carotid endarterectomy to correct asymptomatic carotid stenosis: ten years later. J Vasc Surg 1987;6:226-30.

47. Treiman RL, Cossman DV, Foran RF, Levin PM, Cohen JL. The risk of carotid endarterectomy for the asymptomatic patient: an argument for prophylactic operation. Ann Vasc Surg 1990;4:29-33.

48. Mattos MA, Hodgson KJ, Londrey GL, et al. Carotid endarterectomy: operative risks, recurrent stenosis, and longterm stroke rates in a modern series. J Cardiovasc Surg 1992;33:387-400.

49. Freischlag JA, Hanna D, Moore WS. Improved prognosis for asymptomatic carotid stenosis with prophylactic carotid endarterectomy. Stroke 1992;23:479-82.

50. Riles TS, Fisher FS, Lamparello PJ, et al. Immediate and long-term results of carotid endarterectomy for asymptomatic high-grade carotid stenosis. Ann Vasc Surg 1994;8:144-9.

51. Executive Committee for the Asymptomatic Carotid Atherosclerosis Study. Endarterectomy for asymptomatic carotid artery stenosis. JAMA 1995;273:1421-8.

52. Hertzer NR, Loop FD, Beven EG, O'Hara PJ, Krajewski LP. Surgical staging for simultaneous coronary and carotid disease: a study including prospective randomization. J Vasc Surg 1989;9:455-63.

53. Kouchoukos NT, Daily BB, Wareing TH, Murphy SF. Hypothermic circulatory arrest for cerebral protection during combined carotid and cardiac surgery in patients with bilateral carotid artery disease. Ann Surg 1994;219:699-706.

54. Gravlee GP, Cordell AR, Graham JE, et al. Coronary revascularization in patients with bilateral internal carotid occlusions. J Thorac Cardiovasc Surg 1985;90:921-5.

55. Babu SC, Shah PM, Singh BM, Semel L, Clauss RH, Reed GE. Coexisting carotid stenosis in patients undergoing cardiac surgery: indications and guidelines for simultaneous operations. Am J Surg 1985;150:207-11.

56. Edwards FH, Clark RE, Schwartz M. Coronary artery bypass grafting: The Society of Thoracic Surgeons National Database experience. Ann Thorac Surg 1994;57:12-9.

\section{Discussion}

Dr. David A. Fullerton (Denver, Colo.). All of us are in the process of carefully scrutinizing the financial aspects of our surgical practices. I believe one of the most effective ways to control costs is to control complications. Stroke is both an expensive and a devastating complication after $C A B G$, and the leading cause of death after CEA is myocardial infarction, so you tackled an extremely difficult and important problem.

Your study is outstanding for a couple of reasons. First, your surgical results are excellent, clearly among the best that have been published. Furthermore, your stroke rate was extremely low despite the fact that you stacked the odds against yourself by using intermittent aortic occlusion, which some suggest increases the risk of stroke during cardiac operations.

Another reason your study is important is that it is extremely difficult to obtain accurate financial data. Your study stands alone in that regard.

Before reading your manuscript I favored a staged procedure, but I think you have argued persuasively that it is safe to do a combined procedure and financially advisable to do so.

I wonder if you might outline a couple of things? Would you now advocate doing a combined procedure on all patients who have both carotid and coronary disease? If not, how do you stratify the surgical strategy? Who should have CEA first and conversely who should have CABG first?

Dr. Daily. I will take the carotid issue separately. The recent study that $I$ just alluded to used the angiographic stenosis figure of $60 \%$ or greater with asymptomatic carotid disease. In that particular study they found a 53\% reduction in ipsilateral stroke over 5 years. I don't think there is much dispute about symptomatic carotid arteries. It has been clear for a long time that these patients significantly benefit by CEA.

I think a patient with significant carotid disease and coronary disease becomes a candidate for a combined procedure provided there are no other surgical considerations, such as mitral valve replacement or contralateral or bilateral occlusion of the carotid arteries. In those cases we do not have survival data or operative data. I think conclusions have to be limited to the same subset that we have reported for the same conclusions to be drawn regarding the safety of the procedure.

Dr. Harold Urschel, Jr. (Dallas, Tex.). In most people's hands combined CEA and CABG has a higher morbidity rate than either alone. Each one of us has to assess whether we can perform with the same proficiency as Dr. Daily and save money. In 1975 at the meeting of The American Association for Thoracic Surgery we presented a group of patients who underwent combined CABG and CEA operations. Indications were based on the anatomy (had to have greater than $60 \%$ diameter restrictions in two dimensions) plus symptoms. It was a clinical decision whether they were had staged or concomitant operations. The same is true today. Since that time we have operated on more than 500 patients with both coronary artery and carotid artery disease. It wasn't until 1986 that we could say that the mortality and morbidity warranted combined, simultaneous procedures. Some patients have bilateral carotid artery disease as well as coronary artery obstruction. In Holland more than 1100 bilateral CEAs were performed simultaneously without higher risk. In our country we do not perform bilateral simultaneous carotid procedures because of the possible injury to the recurrent laryngeal nerve and the malpractice environment. However, on the basis of cost, I'm sure the health maintenance organizations would favor performing simultaneous bilateral CEAs to save the $23 \%$ requiring a second operation. This might also be indicated in the patient with coronary artery disease. It is important that the same surgical team perform both operations. If you bring in a separate carotid vascular team, you cannot stay under 30 minutes for each carotid procedure. Each of us should look carefully at our own results in evaluating Dr. Daily's data before we try to emulate it.

Dr. D. Craig Miller (Stanford, Calif.). What was the 
difference in operative time for the combined versus the single operations?

Dr. Daily. The additional time for the CEA really was just for the performance of the incision to expose the artery and for the CEA itself, because the incision for the carotid artery was closed simultaneously with the sternotomy incision. I would say the additional time was 30 minutes or less.

Dr. Steven Guyton (Seattle, Wash.). One of the important concerns here is who is saving money. In this situation Medicare certainly saves money because they do not have to pay out more for the CABG. However, one of the concerns that will come up I'm sure is that for your hospital there is a certain margin when you perform
CABG. By increasing the costs of the operation because of the additional time in the operating room or additional potential complications, which you did not have but many people do, you may wipe out that margin. You may find that as you combine procedures like this you increase the volume of cases, but by doing more cases and having no margin you may wipe out the economic viability of surgical practices or hospitals. It is very important to understand that the costs associated with surgery are the costs that are incurred by the institutions that are performing them, not the institutions that are paying for them.

Dr. Daily. I believe that the institution in which the procedure is performed would have to separately consider the financial consideration.

\section{Bound volumes available to subscribers}

Bound volumes of The Journal of Thoracic and Cardiovascular Surgery are available to subscribers (only) for the 1996 issues from the Publisher, at a cost of $\$ 100.50$ for domestic, $\$ 128.94$ for Canadian, and $\$ 120.50$ for international subscribers for Vol. 111 (January-June) and Vol. 112 (July-December). Shipping charges are included. Each bound volume contains a subject and author index and all advertising is removed. Copies are shipped within 60 days after publication of the last issue of the volume. The binding is durable buckram with the Journal name, volume number, and year stamped in gold on the spine. Payment must accompany all orders. Contact Mosby-Year Book, Inc., Subscription Services, 11830 Westline Industrial Drive, St. Louis, Missouri 63146-3318, USA; phone 800-453-4351 or 314-453-4351.

Subscriptions must be in force to qualify. Bound volumes are not available in place of a regular Journal subscription. 